\title{
Analysis of Factors Affecting User Willingness to Use Virtual Online Education Platforms
}

\author{
https://doi.org/10.3991/ijet.v17i01.28713 \\ Xiaogai Shen ${ }^{(\varpi)}$, Jianli Liu \\ Shijiazhuang University of Applied Technology, Shijiazhuang, China \\ shenxg@sjzpt.edu.cn
}

\begin{abstract}
With the growing recognition and acceptance of virtual online education, more and more educational institutions are switching from offline business to online business. However, users differ in their willingness to use virtual online education platforms. This paper explores the factors affecting user willingness to use such platforms, laying a theoretical basis for promoting virtual online education. The main findings are as follows: college students are positive and in favor of extracurricular learning; the students' demand for online learning contents varies with gender, grade, and major; the long-term willingness to use depends on perceived usefulness, satisfaction, and perceived switching cost, of which the last factor is the key contributor to increasing user resistance; the long-term willingness to use online education platforms is influenced by perceived usefulness, expected confirmation, content quality, service quality, system quality, satisfaction, and perceived switching cost, etc.
\end{abstract}

Keywords — online education, user willingness, perceived switching cost, perceived usefulness, satisfaction

\section{Introduction}

The teacher-centered offline teaching mode in traditional education can no longer meet the demand of modern people to acquire knowledge anytime and anywhere [1, 2]. The online teaching and learning mode breaks through the limitations of time and space, which has well made up for the shortcomings of traditional education in this aspect [3]. Now, the online education industry has received strong support from government, and the online education platforms have shown bright prospects in terms of customer demand, science and technology development, and policy support [4, 5].

At present, online education platforms have emerged and developed rapidly in response to the proper time and conditions, and the various online education platforms represented by MOOC have been favored by scholars and students [6]. By analyzing the data of online behavior logs of users on the online education platforms, researchers in the computer industry can find out the reasons why users like a type of class or not, and figure out the decisive factors affecting the learning preferences of users, then, the educational resources could be recommended to platform users in a more targeted manner and help them improve learning efficiency [7, 8]. The online educa- 
tion industry has a good outlook, the user number and industry scale both grow fast, attracting widespread attention from various industries $[9,10]$. However, accompanying the increasing number of users, platforms, and institutions, a few problems have arisen as well, such as the poor user experience, the low user stickiness, and the mismatch between user demand and existing courses, etc. [11, 12]. Then, how to break through these development dilemmas of the industry, and how to improve user experience, satisfaction, and stickiness have become issues that the operators of these online education platforms should consider [13]. There are many factors that can affect the online education platforms, after research, scholars pointed out that, if the online education platforms want to stand out from the crowd, they must start from the online education products and have a thorough understanding of the actual requirements and behavior characteristics of the users, only in this way can they design products that can meet the expectations of users, thereby offering satisfactory and quality service for their users $[14,15]$.

Viewing from the perspective of the development of virtual online education industry, after a few years of fast development, now this industry has entered a stable development stage, operators of the platforms can also propose optimization strategies for improving user experience, helping the online education industry to break through the development bottleneck, and ultimately achieving the goals of optimizing education mode, improving education level, and realizing education equity $[16,17]$. Some scholars found that "perceived openness" and "perceived interest" are the two core factors affecting users' willingness to continue their using behavior. Only two variables, pleasure and ease of use, have a significant impact on behavior willingness; however, the impact of perceived goals, content, and equipment conditions on behavior willingness hasn't been proved yet $[18,19]$. Taking virtual online education platforms as subjects, this paper attempts to explore factors affecting the user willingness, in the hopes of providing theoretical evidences for better developing the virtual online education platforms and the online education industry.

\section{A theoretical study of the acceptance behavior of online education}

The devices of online learning can be divided into mobile terminals, computer terminals and TV terminals, generally, college students have personal computers and mobile phones [20]. The mobile terminals can surpass the restrictions of time and space; as long as the mobile devices can access the wireless network or have cached online courses, they can meet the learning requirements of college students to study anytime and anywhere [21,22]. Only when the learning requirements of college students have transformed into education demand, can they conduct the behaviors of searching for educational resources and related services and then using these resources [23, 24]. Figure 1 gives a diagram of the Theory of Planned Behavior (TPB). By adding control variables, the objectivity of the model could be improved, thereby obtaining the theory of planned behavior. First, the control beliefs of the resources 
and opportunities required to take actions have been increased; Second, the variable of perceptual behavior control has been increased [25, 26].

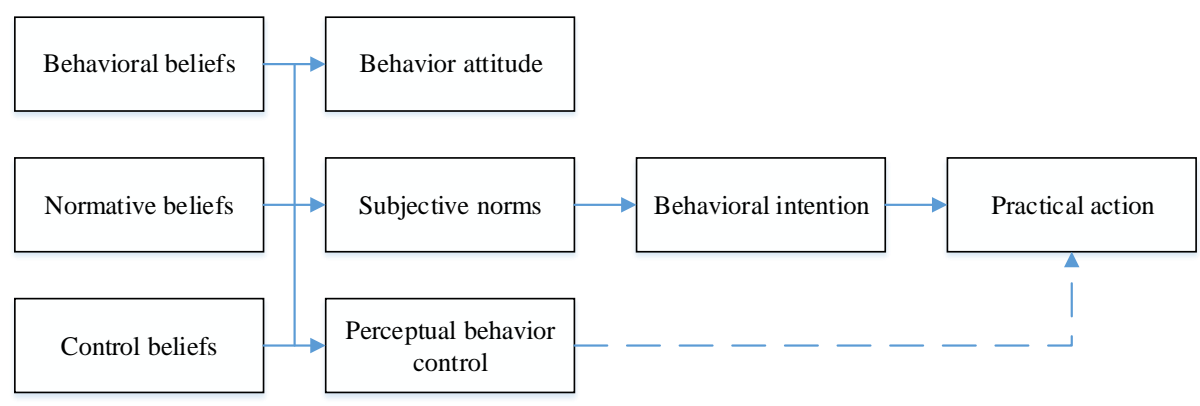

Fig. 1. Theory of planned behavior

The virtual online education has been promoted based on three things: idle educational resources, online education platforms, and user participation. Without online education platforms, online education mode couldn't be implemented [27]. The availability of the use rights of online education products, and the usefulness of online education products are two things most concerned by online education platform users [28]. The advantages of online education have well satisfied the users' concerns about the access to use rights [29]. Figure 2 shows the initial hypothesis model of educational resource acquisition. The users' willingness to use online education is determined by perceived ease of use, perceived usefulness, access convenience, individual innovation, and social influence. Control variables include gender, age, education, and spending limit, etc. When an individual finds that people around him/her are using online education products and have achieved their personal goals via the behavior of using online education, he/she will have a positive attitude towards these products [30]. Researchers found that both the perceived ease of use and perceived usefulness have a positive influence on users' willingness to use online education products, and the perceived ease of use has a positive influence on perceived usefulness [31]. Social influence has a positive impact on users' willingness to use online education and on the perceived usefulness [32]. Individual innovation and access convenience both have a positive influence on users' willingness to use online education, and on the perceived ease of use and perceived usefulness [33, 34]. 


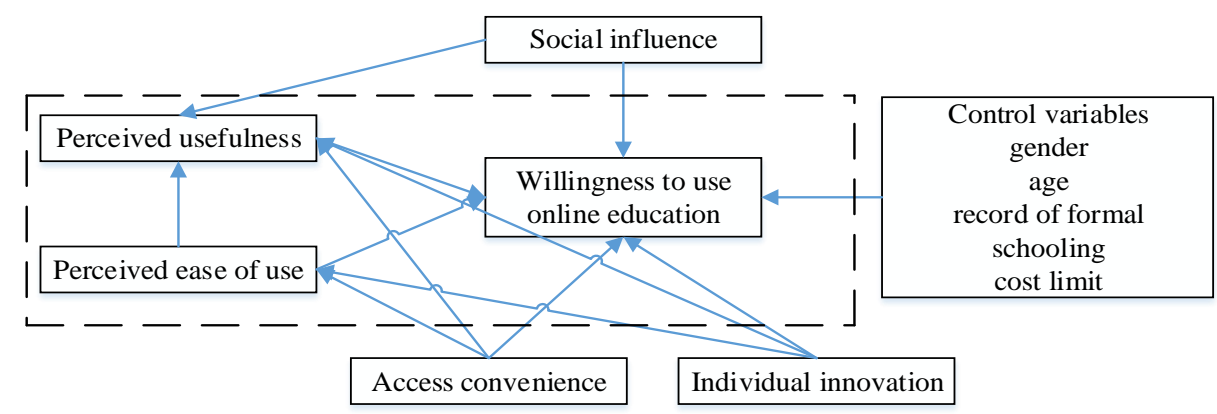

Fig. 2. Initial hypothesis model of educational resource acquisition

\section{Current state of college students' online learning}

\subsection{Survey objects and methods}

The advances in Internet technology have given online education a great opportunity for development. Figure 3 shows the statistics on the market scale of China's virtual online education industry in recent years. Last year, the total market size of online education in China reached 300 billion yuan, the growth rates of each year all exceeded $10 \%$, the trend is very good. In order to figure out the current state of college students' online learning, our research team conducted a survey Hebei province. The survey objects are college students of all grades. Information such as their gender, age, and major were collected through the survey. A total of 450 questionnaires were distributed and 415 valid questionnaires were returned. The questionnaire was designed to find out the respondents' basic information, and their cognition and current state of extracurricular learning and online learning (Table 1). 


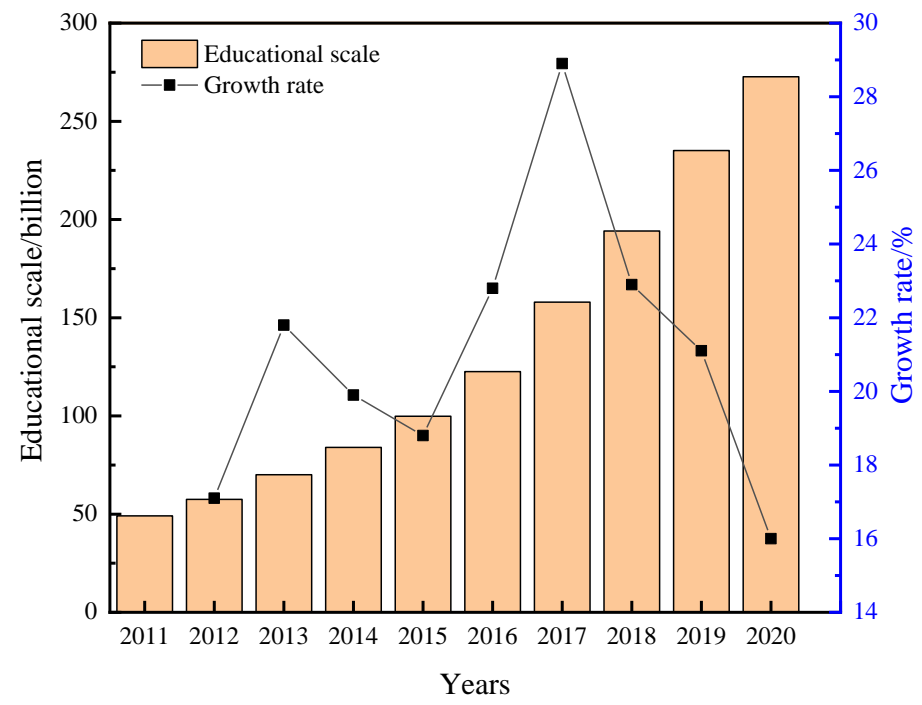

Fig. 3. Statistics on the market scale of China's virtual online education industry in recent years

Table 1. Information of survey objects

\begin{tabular}{|l|c|c|c|}
\hline \multirow{2}{*}{ Item } & Category & Number & Proportion/\% \\
\hline \multirow{3}{*}{ Gender } & Male & 221 & $53.25 \%$ \\
\hline \multirow{3}{*}{ Grade } & Female & 194 & $46.75 \%$ \\
\cline { 2 - 4 } & Freshman & 121 & $29.16 \%$ \\
\cline { 2 - 4 } & Sophomore & 97 & $23.37 \%$ \\
\cline { 2 - 4 } & Junior year & 86 & $20.72 \%$ \\
\cline { 2 - 4 } & Senior year & 111 & $26.75 \%$ \\
\hline \multirow{2}{*}{ Professional category } & Liberal arts & 183 & $44.10 \%$ \\
\cline { 2 - 4 } & Science and engineering & 232 & $55.90 \%$ \\
\hline
\end{tabular}

\subsection{Analysis of survey results}

Figure 4 shows the survey results of college students' attitudes toward extracurricular learning. According to the figure, we can see that, more than $80 \%$ of college students believe that extracurricular learning is very important or important, and only $3.77 \%$ of them think it is not important at all; overall, they hold a positive and agreeable attitude towards extracurricular learning. 


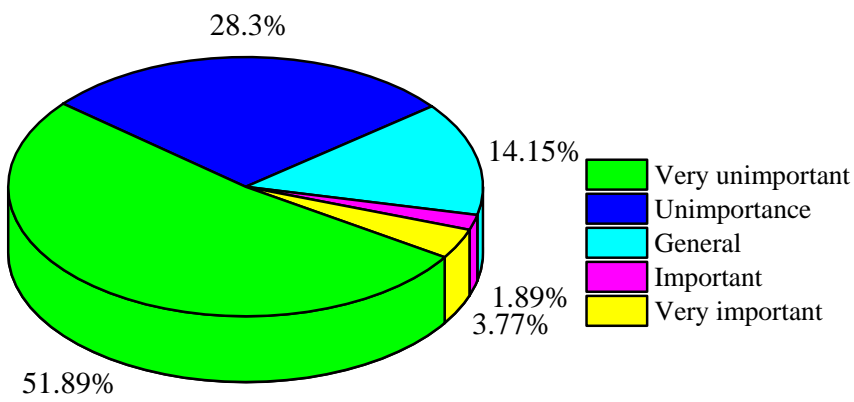

Fig. 4. College students' attitudes toward extracurricular learning

Figure 5 shows the survey results of the current state of college students' extracurricular learning. About $95 \%$ of them conduct extracurricular learning every week; most of them spend 1-10 hours on extracurricular learning, accounting for $41.18 \%$; and $32.35 \%$ of them spend $10-20$ hours on extracurricular learning every week. This indicates that college students approve of extracurricular learning with their real actions. Figure 6 shows ways for users to know of the online education platforms. The many ways include friend recommendation, network recommendation, comparison of their own use experience, advertisement, and third-party application store recommendation, etc.

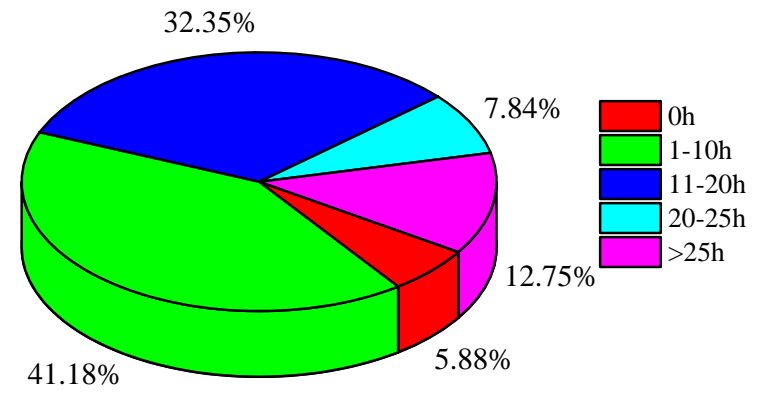

Fig. 5. Current state of college students' extracurricular learning 


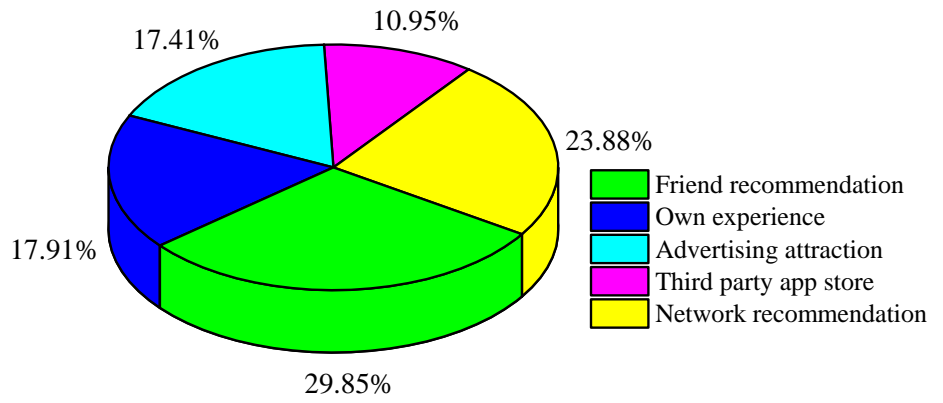

Fig. 6. Ways for users to know of the online education platforms

With its unique advantages, virtual online education is very attractive to students, and what the platforms need to do is to improve their service quality to retain existing users. Figure 7 shows the types of online learning courses taken by college students. Main course types are skill certificate examination courses and software programming courses. College students do use online education to improve their strength and professional abilities, and other course types include extended courses, language courses, art \& interest courses, etc.

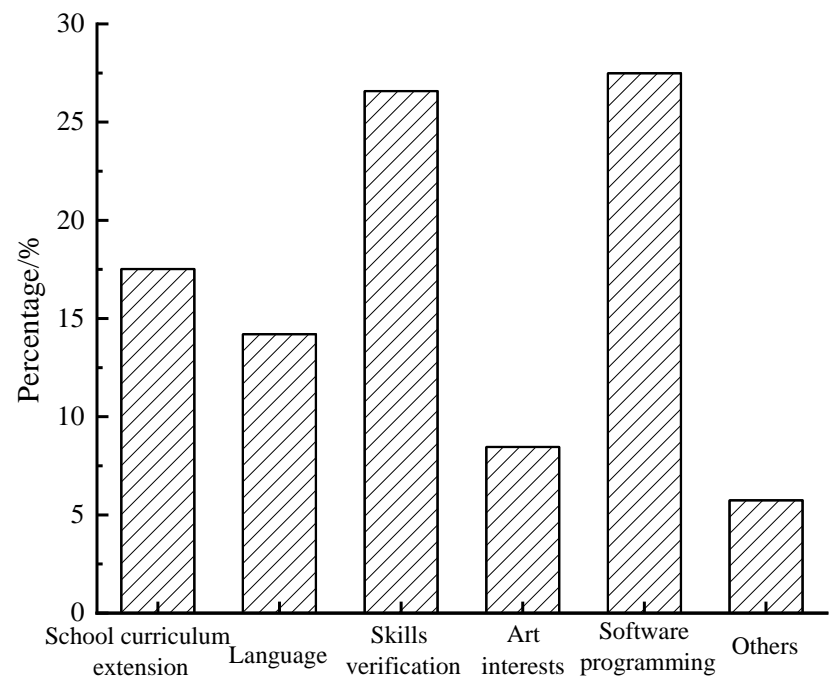

Fig. 7. Types of online learning courses taken by college students

Figure 8 shows the influence of different factors on the course type selection of college students. Figure 8(a) shows the influence of the gender factor, male students take more skill certificate examination courses and software programming courses than female students; while in terms of extended courses, language courses, and art \& interest courses, the proportion of male students is lower than that of female students. 
Figure 8 (b) shows the influence of the grade factor, according to the figure, junior year college students take more skill certificate examination courses and software programming courses than students of other grades, which has something to do with their employment pressure; freshman students take more extended courses and art \& interest courses than students of other grades. Figure 8(c) shows the influence of the major factor, as can be seen from the figure, liberal arts majors and science majors have different emphases in extracurricular learning; liberal arts majors take more extended courses, language courses, and art \& interest courses than science majors; while the science majors take more skill certificate examination courses and software programming courses than liberal arts majors.

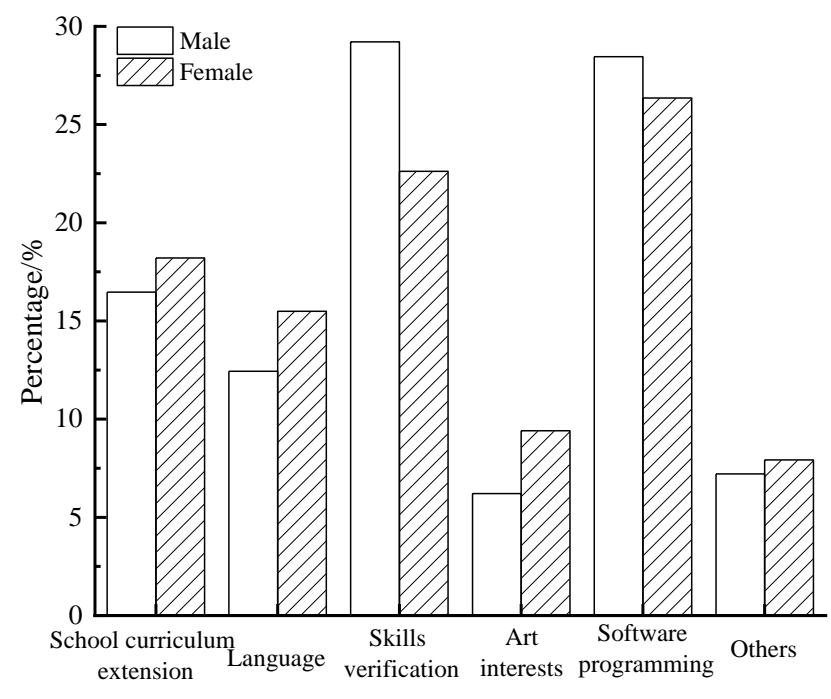

a) Influence of the gender factor 


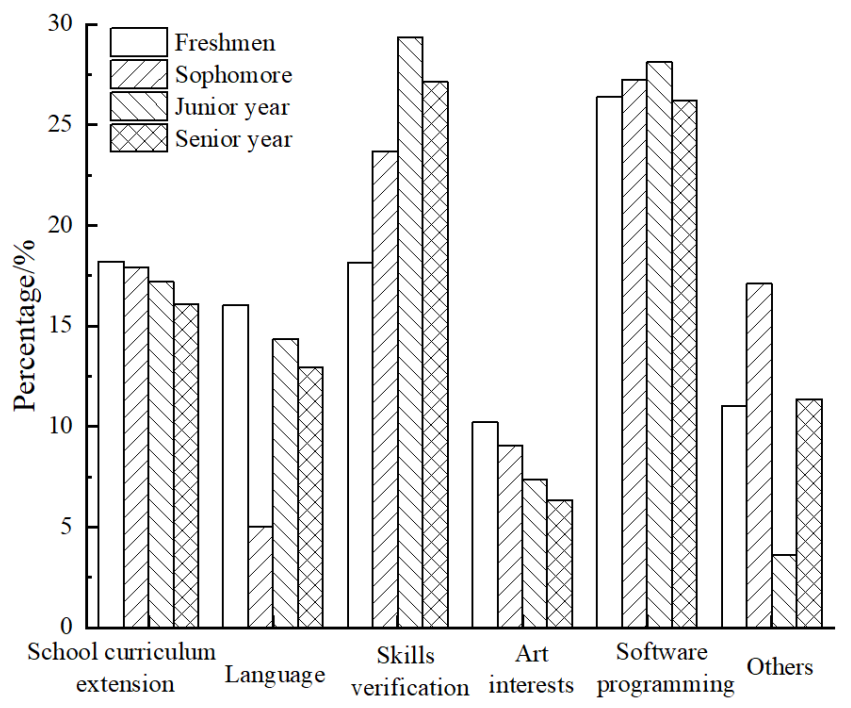

b) Influence of the grade factor

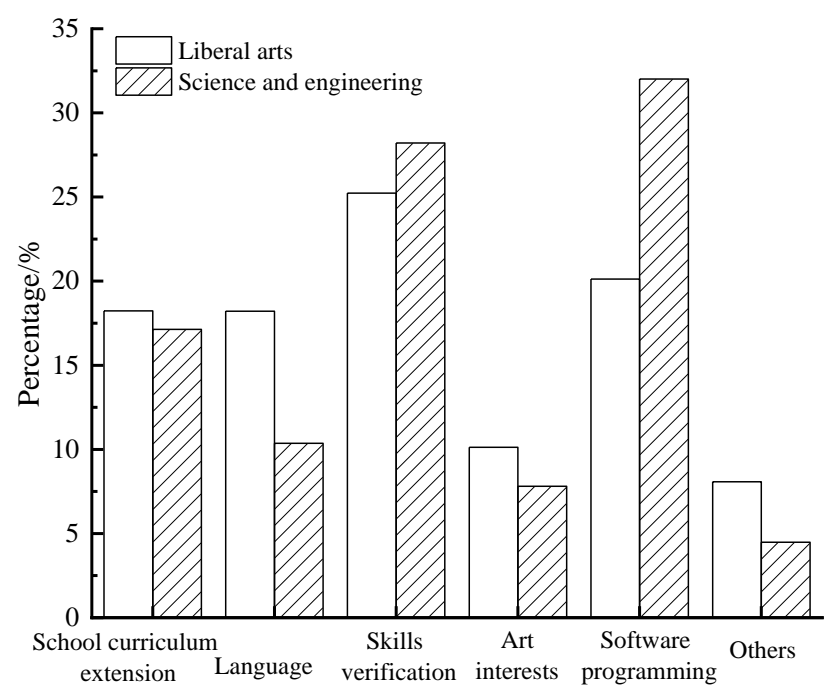

c) Influence of the major factor

Fig. 8. Influence of different factors on the course type selection of college students 


\section{$4 \quad$ Analysis of factors affecting users' willingness to continue to use virtual online education platforms}

\subsection{Proposal of influencing factors}

For online education, many factors can influence user willingness, such as the educational nature of the course, content richness, course type, operation interface, learning method preference, learning enthusiasm, and whether charge of courses is reasonable, etc. Figure 9 shows the user preference model of online educational resources, which can be summarized into three aspects: usefulness, reliability, and cost. Usefulness contains the academic information, subject interest, and topic interest. Reliability contains media category, form quality, and content quality. Cost contains application practice, acquisition cost, data duration, and learning basics. Figure 10 shows the factors affecting users' willingness to continue to use online education platforms, including perceived usefulness, expected confirmation, content quality, service quality, system quality, satisfaction, perceived switching costs, and willingness to continue.

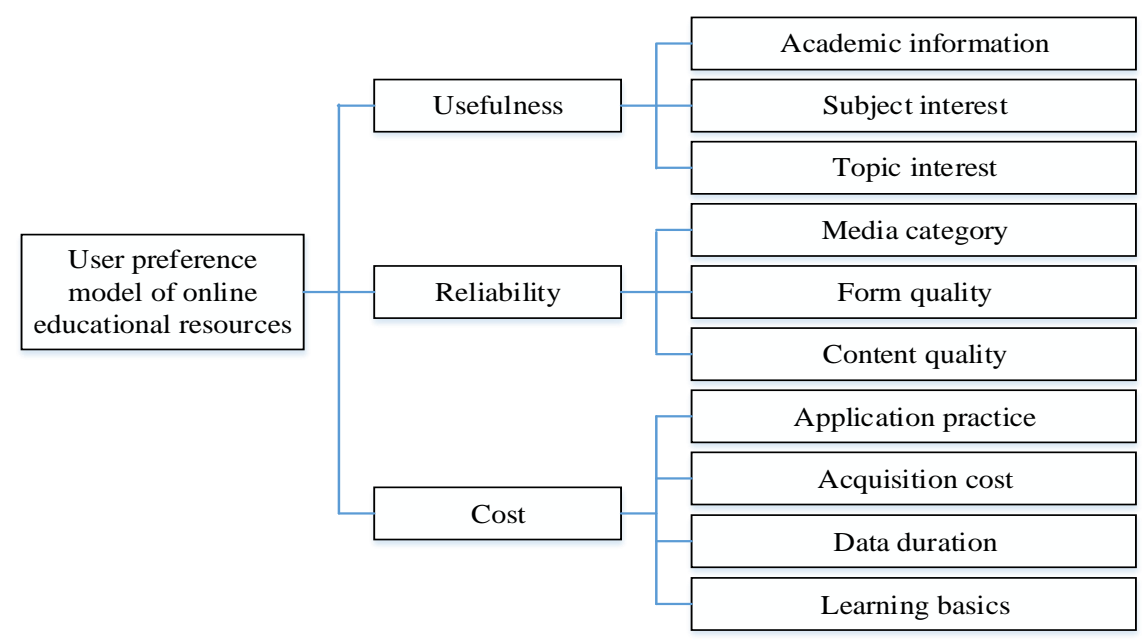

Fig. 9. The user preference model of online educational resources 


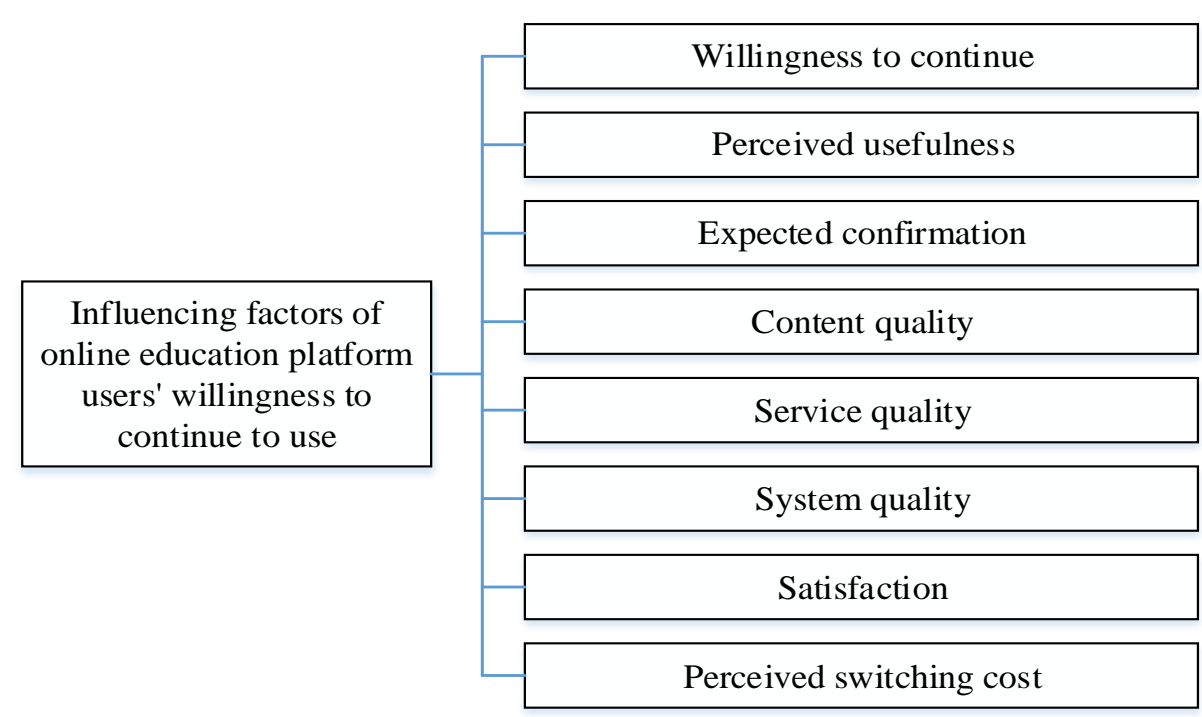

Fig. 10.Factors affecting users' willingness to continue to use online education platforms

\subsection{Analysis of the sample data of influencing factors}

Figure 11 gives a diagram explaining how the factors listed above influence the willingness of online education platform users. Expected confirmation and content quality can affect users' perceived usefulness and satisfaction; service quality, system quality, and perceived usefulness can affect the satisfaction of users; perceived usefulness, satisfaction, and perceived switching cost determine the user's willingness to continue to use the online education platforms; perceived switching cost plays a key role in increasing user resistance. Information quality, service quality, and system quality are three important variables of a successful information system model, all three variables have a positive correlation with user satisfaction. When users use the online platforms for learning, before purchasing the courses, the pre-purchase desire negatively affects the degree of expected confirmation; the greater the pre-purchase desire, the lower the degree of expected confirmation after purchase. The postpurchase perceived performance positively affects the degree of expected confirmation; the higher the post-purchase perceived performance, the higher the degree of expected confirmation. 


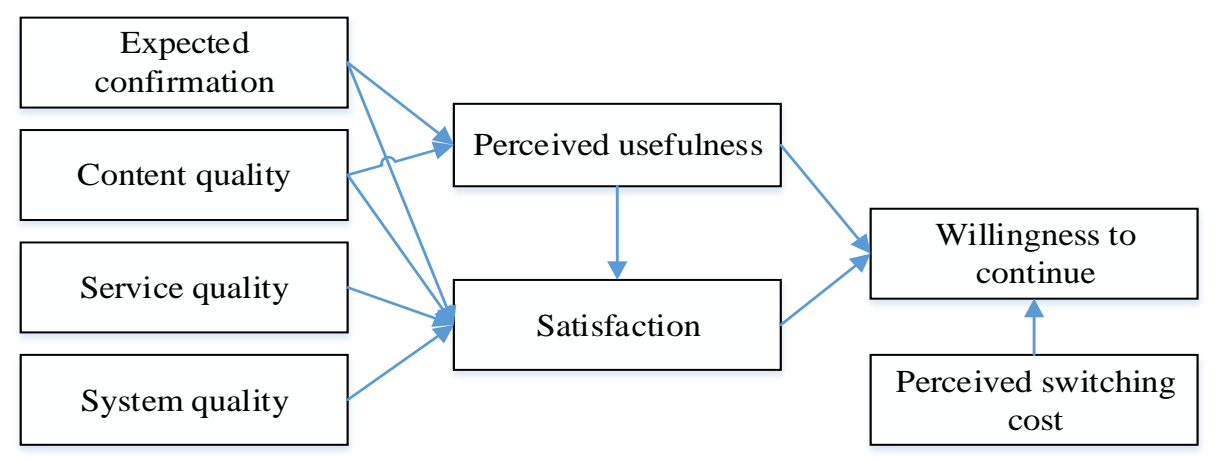

Fig. 11.How factors influencing the willingness of online education platform users

\subsection{Strategies to prompt users to choose online education platforms}

By analyzing the factoring affecting the willingness of users and combining with the actual situations of the promotion and application of online education platforms, this paper proposes following strategies to prompt user willingness from the perspective of platform developers. Figure 12 lists the proposed strategies that give detailed suggestions from three aspects of operation, pricing, and development. In terms of operational strategies, in order to promote brand image, investment in advertising should be increased, a public opinion management department could be established to maintain and protect the image of the company, and the service department could be expanded to improve after-sales service. In terms of pricing strategies, some low-cost or free courses could be launched; comprehensive consideration should be given to the cost and the price of some online courses should be raised (a set of reasonable online course prices should be determined based on market research, cost analysis, and competition analysis); some preferential promotion activities should be held from time to time to promote payment conversion. In terms of development strategies, update frequency should be increased to optimize the operation interfaces of the platforms, intelligent learning systems could be developed to help users improve their learning effect, and more personalized courses could be developed and launched. 


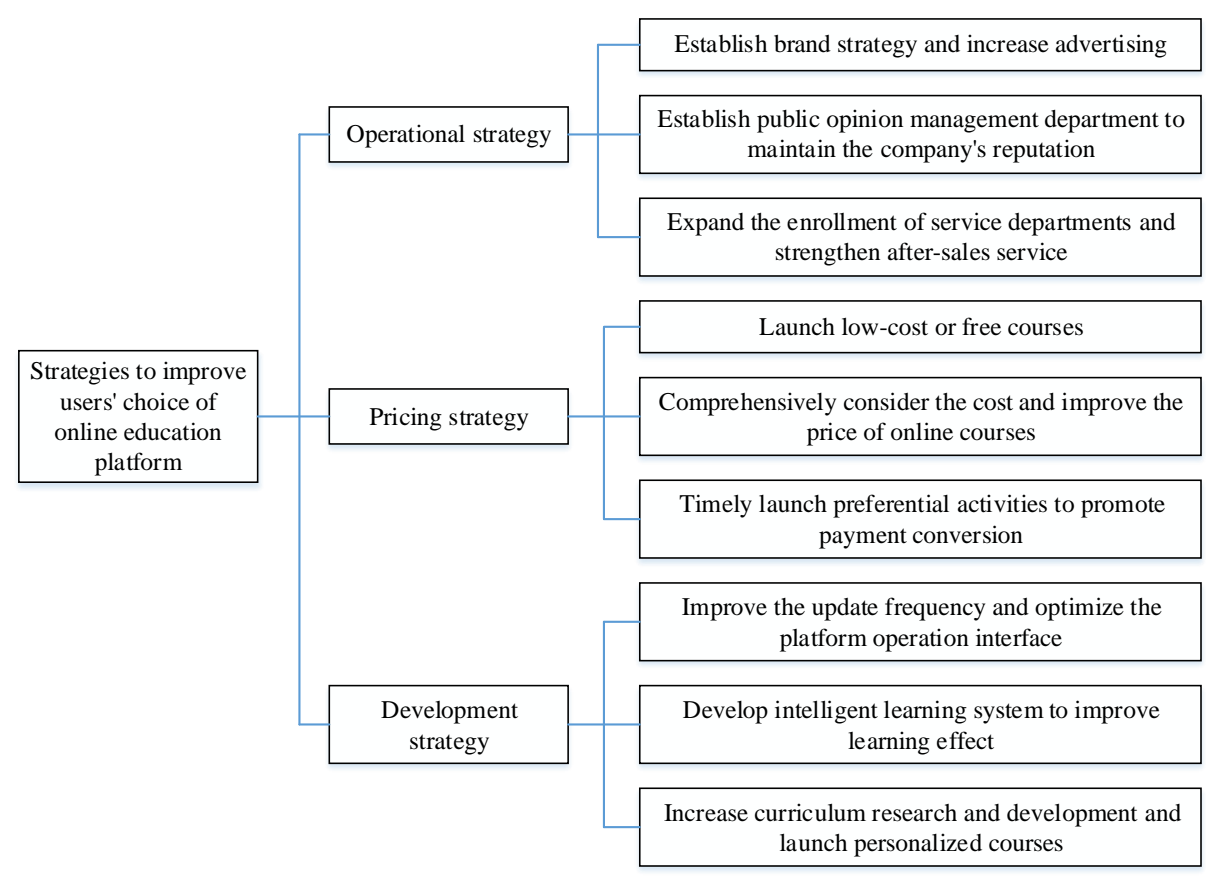

Fig. 12.Strategies for online education platforms to prompt user willingness

\section{Conclusions}

Taking virtual online education platforms as subjects, this paper explored factors affecting user willingness and provides useful evidences for better developing and promoting the virtual online education platforms. The specific conclusions are:

1. College students are positive and in favor of extracurricular learning. The main course types chosen by college students on the online education platforms are skill certificate examination courses and software programming courses, and they do use these platforms to improve their own strength and professional abilities.

2. Factors affecting users' willingness to continue to use the online education platforms include: perceived usefulness, expected confirmation, content quality, service quality, system quality, satisfaction, perceived switching cost, and willingness to continue.

3. Perceived usefulness, satisfaction, and perceived switching cost determine the users' willingness to continue to use the online education platforms; the perceived switching cost plays a key role in increasing user resistance.

4. To improve user willingness, online education platforms need to continuously improve themselves using operational strategies, pricing strategies, and development strategies, thereby gaining high user satisfaction. 


\section{References}

[1] Yalagi, P.S., Dixit, R.K., Nirgude, M.A. (2021). Effective use of online teaching-learning platform and mooc for virtual learning. Journal of Physics: Conference Series, 1854(1): 012019. https://doi.org/10.1088/1742-6596/1854/1/012019

[2] Hua, S.Y., Ren, Z.W. (2021). "Online + Offline" Course Teaching Based on Case Teaching Method: A Case Study of Entrepreneurship Education Course, International Journal of Emerging Technologies in Learning, 15(10): 69-85. https://doi.org/10.3991/ijet.v15i10. $\underline{13999}$

[3] Liu, H.B., Liu, Y., Xu, L., Abdullah, S. (2021). Multi-attribute group decision-making for online education live platform selection based on linguistic intuitionistic cubic fuzzy aggregation operators. Computational and Applied Mathematics, 40(1): 16. https://doi. org/10.1007/s40314-020-01406-1

[4] Shraim, K.U. (2020). Quality Standards in Online Education: The ISO/IEC 40180 Framework, International Journal of Emerging Technologies in Learning, 15(9): 22-36. https://doi.org/10.3991/ijet.v15i19.15065

[5] Osamnia, M., Okada, H., Berena, A. J., Ueno, H., Chunwijitra, S. (2016). A novel automated course generation system embedded in the online lecturing platform for higher education. Computer Applications in Engineering Education, 24(4): 586-598. https:// doi.org/10.1002/cae.21734

[6] Ray, J.A. (2009). An investigation of online course management systems in higher education: platform selection, faculty training, and instructional quality. International Journal of Information \& Communication Technology Education, 5(2): 117-132. https:// doi.org/10.4018/jicte.2009040105

[7] Singh, A.K., Kumar, S., Bhushan, S., Kumar, P., Vashishtha, A. (2021). A proportional sentiment analysis of MOOCs course reviews using supervised learning algorithms. Ingénierie des Systèmes d'Information, 26(5): 501-506. https://doi.org/10.18280/isi. $\underline{260510}$

[8] Permana, I.S., Hidayat, T., Mahardiko, R. (2020). Users' intentions and behaviors toward portable scanner application - do education and employment background moderates the effect of UTAUT main theory?. Journal of Physics: Conference Series, 1803(1): 012034. https://doi.org/10.1088/1742-6596/1803/1/012034

[9] Tantawi, M.E., Aljameel, A., Fita, S., Alsahan, B., Alsuwaiyan, F., Meligy, O.E. (2019). Dentists' intentions to manage drug users: role of theory of planned behaviour and continuing education. European Journal of Dental Education, 23(3): 364-372. https://doi. org/10.1111/eje. 12438

[10] Sun, Y., Chai, R.Q. (2020). An early-warning model for online learners based on user portrait. Ingénierie des Systèmes d'Information, 25(4): 535-541. https://doi.org/10. $\underline{18280 / i s i .250418}$

[11] Chiu, W., Cho, H. (2020). The role of technology readiness in individuals' intention to use health and fitness applications: a comparison between users and non-users. Asia Pacific Journal of Marketing and Logistics, 33(3)" 807-825. https://doi.org/10.1108/APJML-092019-0534

[12] Wu, C.H., Chen, S.C. (2015). Understanding the relationships of critical factors to facebook educational usage intention. Internet Research, 25(2): 262-278. https://doi.org/ 10.1108/IntR-11-2013-0232

[13] Kirk, E., Gerlak, A.K. (2016). Teaching collaborative governance online: aligning collaborative instruction with online learning platforms. Journal of Public Affairs Education, 22(3): 327-344. https://doi.org/10.1080/15236803.2016.12002251 
[14] Crowley-Barnett, J., Pagano, T., Kent, M. (2020). Engaging perioperative learners using online game-ased education. AORN Journal, 112(5): 447-456. https://doi.org/10.1002/ aorn.13206

[15] Mokkenstorm Jan, K., Merelle, S.Y.M., Smit J.H. (2019). Exploration of benefits and potential harmful effects of an online forum for visitors to the suicide prevention platform in the netherlands. Crisis, 41(3): 205-213. https://doi.org/10.1027/0227-5910/a000627

[16] Xu, W., Zhou, Y. (2020). Course video recommendation with multimodal information in online learning platforms: a deep learning framework. British Journal of Educational Technology, 51(5), 1734-1747. https://doi.org/10.1111/bjet.12951

[17] Liu, J. (2021). Design of flipped classroom mode for ideological and political education based on online multimedia platform. Journal of Physics Conference Series, 1744(4): 042145. https://doi.org/10.1088/1742-6596/1744/4/042145

[18] Chen, Y.H., Keng, C.J. (2018). Utilizing the push-pull-mooring-habit framework to explore users' intention to switch from offline to online real-person english learning platform. Internet Research, 29(1): 167-193. https://doi.org/10.1108/IntR-09-2017-0343

[19] Duan, X., Dai, L. (2018). Study on the relationship between experience quality, co-created value and users' behavioral intention of making continuous contributions on internet ugc platforms. Journal of Service Science and Management, 11(2): 267-277. https://doi. org/10.4236/jssm.2018.112019

[20] Bao, Z., Shang, B. (2021). Self-efficacy and continuance intention of web 2.0 platforms: a meta-analysis. Data Technologies and Applications, 55(4): 511-526. https://doi.org/ 10.1108/DTA-02-2020-0047

[21] Xiao, L., Ke, T. (2019). The influence of platform incentives on actual carriers' continuous participation intention of non-vehicle operating carrier platform: a study in china. Asia Pacific Journal of Marketing and Logistics, 31(5): 1269-1286. https://doi.org/10. 1108/APJML-06-2018-0227

[22] Zhou, T. (2020). The effect of information privacy concern on users' social shopping intention. Online Information Review, 44(5): 1119-1133. https://doi.org/10.1108/OIR-092019-0298

[23] Kim, H., Shin, D.H. (2017). The effects of platform as a technology standard on platformbased repurchases. Digital Policy, Regulation and Governance, 19(2): 41-55. https://doi. org/10.1108/DPRG-11-2016-0054

[24] Wang, H., Fang, H., Tang, Q. (2019). Exploring the role of technical features in promoting the intention to continue sharing contents in social commerce platform. Journal of Service Science \& Management, 12(2): 214-233. https://doi.org/10.4236/jssm.2019.122015

[25] Yu, Y. (2021). Design of mobile learning service platform based on data mining. Journal of Physics Conference Series, 1757(1): 012134. https://doi.org/10.1088/1742-6596/1757/ $\underline{1 / 012134}$

[26] Casalicchio, G., Bossek, J., Lang, M., Kirchhoff, D., Kerschke, P., Hofner, B. (2017). Openml: an $\mathrm{R}$ package to connect to the machine learning platform openml. Computational Statistics, 34(3): 33. https://doi.org/10.1007/s00180-017-0742-2

[27] Shaw, C., Larson, R., Sibdari, S. (2014). An asynchronous, personalized learning platformguided learning pathways (GLP). Creative Education, 5(13): 1189-1204. https://doi. org/10.4236/ce.2014.513135

[28] Wang, X., High, A., Wang, X., Zhao, K. (2020). Predicting users' continued engagement in online health communities from the quantity and quality of received support. Journal of the Association for Information Science and Technology, 72(6): 710-722. https://doi.org/ $\underline{10.1002 / \text { asi. } 24436}$ 
[29] Bhagat, K.K., Wu, L.Y., Chang, C.Y. (2016). Development and validation of the perception of students towards online learning (POSTOL). Journal of Educational Technology \& Society, 19(1), 350-359. https://doi.org/10.1037/t64255-000

[30] Emang, D.W.A.B., Lukman, R.N.I.R., Kamarulzaman, M.I.S., Zaaba, Z.F. (2017). Usability studies on e-learning platforms: Preliminary study in USM. AIP Conference Proceedings, 1891(1): 020040. https://doi.org/10.1063/1.5005373

[31] Zhao, D.Y. (2011). E-learning platform and modern education. International Journal of eEducation, e-Business, e-Management and e-Learning, 1(2): 139-143. https://doi. org/10.7763/IJEEEE.2011.V1.22

[32] Hsu, C.M. (2014). The construction of a web-based learning platform from the perspective of computer support for collaborative design. International Journal of Online Pedagogy and Course Design, 3(4): 44-67. https://doi.org/10.4018/ijopcd.2013100104

[33] Chu, S.K.W., Siu, F., Liang, M., Capio, C.M., Wu, W.W. (2013). Users' experiences and perceptions on using two wiki platforms for collaborative learning and knowledge management. Online Information Review, 37(2): 304-325. https://doi.org/10.1108/OIR-03 $-2011-0043$

[34] Wang, C.H., Shannon, D.M., Ross, M.E. (2013). Students' characteristics, self-regulated learning, technology self-efficacy, and course outcomes in online learning. Distance Education, 34(3): 302-323. https://doi.org/10.1080/01587919.2013.835779

\section{Authors}

Xiaogai Shen, graduated from Beijing Forestry University and obtained master degree of Engineering in 2010; from 2003, she works in Shijiazhuang University of Applied Technology. Her main research fields are computer application and computer science technology.

Jianli Liu, received his Master's degree in engineering from University of Electronic Science and Technology of China. He has been teaching in Shijiazhuang University of Applied Technology since 2002. His main research area is business administration (Email: liujl@sjzpt.edu.cn).

Article submitted 2021-11-08. Resubmitted 2021-12-10. Final acceptance 2021-12-14. Final version published as submitted by the authors. 